This is an Accepted Manuscript of an article published by Wiley in Area online 10 December 2016, available

online: http://onlinelibrary.wiley.com/doi/10.1111/area.12320/full

\title{
Changing Ethnographic Mediums: The Place-Based Contingency of Smartphones And Scratchnotes
}

\author{
Richard Gorman \\ School of Geography and Planning, Cardiff University, Cardiff CF10 3WT \\ Email: gormanr@cardiff.ac.uk
}

The medium by which ethnographic notes are taken within the field is changing. Increasingly researchers are turning to jotting short notes using smartphone notation apps, leaving pen and paper behind. While this has practical benefits, there is a need to recognise explicitly how the medium by which notes are taken can influence the content, style and practice of contemporaneous ethnographic note-taking. There is a place-based contingency to the acceptability of the smartphone as a research tool; phones carry different social connotations to paper notebooks, and can act to reinforce difference, making statements of privilege, power and culture. The medium by which fieldnotes are taken actively impacts the field and is capable of influencing relationships with participants and altering the power dynamic of research. The changing tools of note-taking also result in a changing visibility of the act of writing, bringing additional challenges to managing consent and ensuring the ethicality of research.

Key words: fieldnotes, ethnography, smartphones, scratchnotes, place, positionality 


\section{Introduction}

Within this article I discuss the changing techno-material environments within, and mediums with, which fieldnotes are taken by researchers conducting participant observation and ethnographic fieldwork. In particular, I explore and critically discuss the place based contingencies and differentials resulting from taking ethnographic fieldnotes via a smartphone (a mobile phone that performs many of the functions of a computer), rather than the more conventional technologies of pen and paper. There is a need to explore how the medium by which fieldnotes are taken influences the field itself, both in terms of the constitution of the field and the actants within the field, but also how the field comes to be represented.

Fieldnotes exist as a form of representation, reducing the events, actants, and places observed to textual accounts that can be reviewed and re-consulted; fieldnotes are the 'raw' material of observation, objectifying events that are situated, ambiguous, and fleeting (Lindlof and Taylor, 2010). The nature and practice of fieldnotes, in spite of their long history and widespread multidisciplinary use, remain contentious; as Jackson (1990) observed in her study of anthropologists' experiences, “what respondents consider to be fieldnotes varies

greatly" (p.6). There is often even a sense of unease around fieldnotes, regarded as a 'backstage' element of research, too revealing and messy to be talked about openly. Emerson et al. (2010) argue that there exists a long-standing neglect in methodological texts ${ }^{1}$ of discussing the actual physical process of writing fieldnotes, with more attention given to issues of gaining access, or producing a 
finished analysis, beginning with already written fieldnotes, rather than discussing the practice of writing original 'close-to-the-field' notes. There is often a sense that fieldnotes are simply produced; phrases such as 'taking notes' and 'doing fieldwork' abound un-interrogated. The consideration that is given to the actual practice of writing fieldnotes is more often than not focussed on an end of the day write-up, rather than the notes taken synchronous to actual observations. Even when the how, where, what, and when of taking fieldnotes is discussed in detail, the medium by which in-the-moment fieldnotes are taken is rarely discussed; this paper attempts to address this.

\section{Scratchnotes}

Scratchnotes (to follow Sanjek's (1990) vocabulary for fieldnotes - Emerson et al. (2010) use the alternative phrase 'jotted notes'), are the first step of fieldnotes, from field perception to paper, providing the primal and foundational moments of ethnographic representation; the raw and original material that is written more or less contemporaneously with the events that are observed and described. Scratchnotes exist as mnemonic keys, shorthand scribblings, and segments of important dialogue, hastily recorded, not full prose, but brief notations and impressions to be expanded on (and importantly, reinterpreted COttenberg, 1990)) later in the construction of 'fieldnotes proper' (Sanjek, 1990).

The act of writing scratchnotes is highly visible. Indeed, some ethnographers use their notepads blatantly, a way of maintaining identity, presenting and reminding participants of their overt scribing role (Emerson et al., 2010), and a means of 
fulfilling expectations - "if you don't write anything down, they think you're not paying attention, or they think they haven't said anything important. So the writing down may be a sign to them that what they're saying is worthwhile" (Jackson, 2015, p. 54). In other field situations, ethnographers rigorously avoid writing in the presence of those studied; the act of writing reminds participants of the fieldworkers' alien presence and secondary motives, influencing the field and relationships within. There is a balance between accurately representing the immediacy of the moment and altering it through one's presence (Emerson et al., 2010).

With the chirography taking place within the field itself, scratchnotes represent a highly visible form of ethnographic writing, and thus the medium by which they are written carries high potential to influence the field, and alter researchparticipant relations. This article thus sets out to explore the research question: how does using a smartphone to take notes influence what happens in the field? I draw on my own experiences conducting ethnographic observation, where I alternated between taking scratchnotes with pen and paper, and writing scratchnotes on my smartphone.

\section{Changing Mediums}

There is a deluge of recent commentary on how emerging digital media and virtual worlds can extend the ethnographic field ${ }^{2}$; using new sources and communication channels for participant observation, and studying social media, email, and text messages as a means of gaining insight and thick description (see Sanjek and 
Tratner's (2015) edited collection), leading to new practices and styles of ethnography. Alongside this, ethnographers are increasingly turning to smartphones as a note-taking medium (Jackson, 2015, Moran, 2015, Tratner, 2015). However, the role and impact that a researcher's own smartphone plays when used as a note-taking medium for, and during, the collection of ethnographic fieldnotes has yet to be interrogated and discussed. Fieldwork has always involved the ethnographer making themselves open to entering relationships with others (Strathern, 1999), we must also recognise the way in which technologies become bound up and enrolled within these relationships technologies are not inert objects, but rather social ties (Bingham, 1996).

In a piece on changes in fieldnote practices, Jackson (2015) discusses how many ethnographers savour the physicality of fieldnotes, harbouring 'special' notebooks in which to commit their representations of the field. Field-notebooks are 'hopelessly romanticised' (Blommaert and Jie, 2010, p. 61); indeed Jackson's participants talk about the tangible nature of their handwritten notes, commenting on the aura and mystique that comes with such physicality, and implied that new technologies decreased the 'precious' nature of fieldnotes. Taking notes on such an everyday ${ }^{3}$ object as a smartphone has the potential to reduce the mystique associated with traditional approaches to research, impacting on the scholarly identity of researchers, and perhaps even influencing a sense of authenticity, correctness, and proper ethnographic procedure. This in itself can challenge the legitimacy of research, troubling expectations and perceptions of the affective 'research encounter' between the ethnographer and participants; a notebook is highly bound up with cultural imaginings of the 
'scientist' or 'researcher'4, whereas the everyday smartphone becomes perceived as 'unscientific' and 'amateur', problematizing issues of keeping participants engaged and feeling valued and respected.

Though too, this everyday-ness of the smartphone presents opportunities to make participants feel more at ease, less unsettling and discomforting than the scientific notebook, less exposing than the all-encompassing Dictaphone. The medium in which fieldnotes are recorded can fundamentally change what happens in the field, influencing relationships between researchers and participants. The fieldworkers' notebook (digital or non) is not merely a notebook, but a bundle of social relations.

Jackson (2015) discusses a case where a researcher took fieldnotes on a smartphone, sending their notes as text-messages to themselves, 'which made the activity invisible - no one nearby noticed anything out of the ordinary' (p.43). Whilst there are certainly milieus where smartphone use is normalised to such an extent, it is overly simplistic to suggest that taking one's fieldnotes via a smartphone is an always invisible process. In fact, jotting notes on a smartphone can be a highly visible practice, capable of altering a researcher's positionality and authority, impacting relationships and interactions with participants, and even influencing the contents and types of scratchnotes taken, as I now move to demonstrate.

\section{Experiences of Writing Smartphone Scratchnotes}


My own ethnographic fieldwork was undertaken at a Community Supported Agriculture $^{5}$ project in Wales, where I explored the role of non-human presence in creating and facilitating therapeutic engagements with place (for a fuller discussion of this work, see (Gorman, 2016)). I was taking an active, participatory, and involved approach in order to create an understanding of the situated perspectives of the participants involved at the farm, and thus regularly pitched in with various agricultural activities. I had chosen to be open about my notetaking on the farm, in order to take more accurate notes at the time of observation, rather than having to scurry off to surreptitiously scribble notes in a toilet (facilities which are few and far between on many community farming projects) à la the classic 'ethnographer's bladder'. Similarly to some of the researchers involved in Jackson's (2015) study of fieldnote practices, I too started out with a special leather pocket-notebook in which to take my fieldnotes in. However, out of convenience I switched to regularly using my smartphone for the writing of short scratchnotes. The ability to jot down key mnemonic phrases single-handedly was a great advantage compared with haphazardly juggling various agricultural tools whilst fumbling for my notebook and pen. I found it much easier to take notes in this way, and it soon became second-nature. There is no doubt that my 'digital nativeness' (Prensky, 2001) influenced this sense of ease, highlighting how our personal selves become bound up in our research practices, our ethnographies are tied to what we know and how we individually make sense of everyday life (Laurier, 2003).

On an affordance level, smartphones (generally) have the added advantage of being sound recorder, digital camera, and video recorder all built into one, making 
a more multi-modal approach to ethnography more accessible and affordable, whilst the everyday nature and familiarity of a smartphone can allow a more accessible navigation and collection of these data types; a smartphone does not require special skills or training in the same way as more specific devices. Certain smartphone note-taking apps come with the ability to collect metadata when taking notes, such as time-stamping entries, facilitating a chronological reconstruction of the day's events when writing fieldnotes proper, using GPS for the geo-tagging of notes, useful if moving through a spatially dispersed field, or even auto capturing and embedding weather, temperature, and even biometric data within notes, which can add additional useful context to the contents of fieldnotes and provide further analytical routes - though there is a need to question whether the phone encourages a focus on different things, modifying the ethnographic gaze.

The physical setting of the field itself can prove challenging to utilising newer technologies to record fieldnotes. Driving rain and mud (frequent occurrences during my fieldwork) are not conducive to taking notes electronically, and whilst notepads too are equally susceptible to being rendered defunct by a passing thunderstorm or a plunge into a puddle, they are arguably more easily replaced. Though at the same time, the ability to email, text, or upload to online storage multiple copies of one's digital scratchnotes as the day progresses - phone reception allowing - becomes something of a boon, making crucial thoughts and memory triggers more retrievable than from a soggy and smudged notepad. In this way, the value which we place on our own tools can force a change in notetaking practice; an observation or exchange in a rainstorm that I would have 
written down in a notebook became relegated to 'headnotes' until it became more congenial to exposing my smartphone.

However, whilst my smartphone was perhaps less than suitable for note-taking in a downpour, there are also places where a paper notebook is equally neither feasible or practical; O'Reilly (2012) gives the example of a researcher conducting fieldwork in 'clubs and discotheques', where keeping short notes on a smartphone was easier than taking pen and paper notes ${ }^{6}$. $0^{\prime}$ Reilly (2012) also comments that the research participants in this instance, 'merely thought he was texting a friend' (p.102), which, returning to Jackson's (2015) comment that the taking of fieldnotes on a smartphone can render the act of note-taking invisible, raises ethical issues and questions of consent. A researcher taking out a notepad and pen is a visual reminder and signifier that the current events are being recorded, whereas I found that when I was taking notes on my phone, participants on the farm presumed that I was disinterested, which led them to forget that they were being observed. Whilst there are certainly benefits here in that this minimizes the awkward interaction that arises when an ethnographer retrieves their notebook midpoint during a conversation, there is a need to recognise that the medium by which notes are taken can actively impact on the ethicality of research, creating a new intermediary between an open and hidden style of ethnography, and forcing new ways of managing relationships with those in the field. In my own work I had to make a conscious effort to remind my colleagues on the farm that I was taking notes (which in itself led to interesting discussions). 
Particular places can be embedded with cultural expectations or legal requirements where note-taking of any kind becomes prohibited. However, smartphones are strong symbols of culture and material practice, intimately bound up with notions of identity, individualism, lifestyle, and sociality (Hjorth et al., 2012a), and thus there are places where it may be more fitting to rely on pen and paper note-taking7 . In certain spatial contexts, phones ${ }^{8}$ may be inaccessible to the ethnographer (hospitals, prisons, courts, etc.) or even given up as a means of symbolically and practically entering the field (Williams, 2016). The use of smartphones within ethnography depends on negotiating local place based contexts.

Indeed, there are all manner of cultural, social, temporal, and place based contingent differentials that problematize the idea of the smartphone being socially acceptable, and thus, a potential note-taking medium; representations of smartphones are not universal. Neither are smartphones isolated artefacts, they are bound up with other debates and tensions, socially and politically constructed, powerfully implicated in a range of issues from the development and locating of phone masts to the thorny issues of privacy and surveillance (Burgess, 2004). For example, in my research I was in a place where a low-tech approach was valued, and there was a conscious rejection of digital technologies and the need to be 'constantly connected', yet I was frequently using my smartphone throughout the day. I worried that it gave the impression I was disinterested in the activities occurring, when in fact, the reason for the recurrent grasping of my smartphone was exactly the opposite. I found that when I stopped to type short phrases into my smartphone as an aide memoire, participants would assume that I had 
completed the task I'd been set, or was bored. It required me to explain to my participants that what they had said was interesting, so I wanted to note it down, I was lucky in that they were delighted to be proving useful and noteworthy, but it is easy to imagine situations and places where this is a more awkward field event. Smartphones have additional technological, cultural, social, political, and economic dimensions (Hjorth et al., 2012a), that must be considered in affecting how a researcher approaches the field. There is a need for researchers to be sensitive to the context of the place they locate themselves in.

How a researcher chooses to record their fieldnotes can actively shape relationships with participants and experiences within the field; humantechnology relations are a large element in the presentation of the self. Desmond (2008, p. 292) discusses how participants found the presence of a tape recorder threatening and invasive, changing their behaviour, which 'violently impacted' the space and the natural sequence being observed. Desmond concludes that rather than allowing the ability to re-produce events precisely, the tape-recorder produced different events in the first place. It highlights the relational nature of technologies, and how they come to be mobilised in different ways in different situations and places, with different forms of relationship developing around them. Similar questions must be asked of smartphone based notation in the field; my regular flourishing of my smartphone often derailed discussions to topics of technology and communication, rather than the agrarian practices I was there to learn about; smartphones modify ethnographic encounters. The physical presence of my phone in-hand also caused others to check their phones (or make them acutely discomforted by their lack of connectedness), serving to alter the 
current emotions in place, triggering or reviving latent worries and concerns, drawing topographically distant actants into 'the field'.

The very medium by which researchers take their notes can act to reinforce a level of difference, making managing and negotiating a level of 'insider status' difficult; phones come to be symbolic representations of their owners (Strocchi, 2003), they announce the user as a particular kind of person (Michael, 2006). For example, my own smartphone (an iPhone 5s) was somewhat out of place on the farm amongst the battered old Nokias capable of making calls and little else; each time I went to take down notes on my phone, I was wary of appearing ostentatious, flaunting and highlighting my difference, reinforcing myself as an outsider. My phone's lack of water-proof and shock-absorbing case further marked it as not belonging on the farm, and by association, me myself; it is not simply the researcher who must 'dress appropriately' (Parr, 1998) to help 'fit in' the field. I was lucky, in that my participants were an exceptionally friendly bunch, and my phone's otherness became an opportunity for joking and rapport building, however, this visible self-othering can force researchers who wish to take open jottings to instead take time out to make their scratchnotes in private, potentially missing fleeting but key interactions, and actively influencing the practice of participant observation. This also highlights the important point that smartphones are not homogenous. Different models and brands have different cultural representations. There is a need when designing and conducting research to pay attention to how the medium by which fieldnotes are collected can change relationships and practice in the field; phones actively mediate our experiences of the environment (Bull, 2015). 


\section{Discussion}

The smartphone exists as an important status symbol and is endowed with social context and meaning, and can thus come to influence a researcher's positionality; research can never escape power relations (Smith, 2003), and even the most ostensibly mundane aspects of research (the tools used to record notes, the clothes worn during) are inextricably linked to dynamics of power. There is a need to recognise how social connotations of digital technologies can affect the place based contingency to the acceptability of smartphones for making scratchnotes and influence researcher-participant interaction. The researcher, and the researchers' tools, are not removed from the research process. Our bodies, clothing, practices (such as smoking or eating), and even non-visual cues and representations (Parr (1998) discusses how the scent of her shampoo set her apart) become intimately intertwined with ethnographic practice, and how we represent ourselves to participants (Parr, 1998).

To draw on Crawford (2012), our smartphones are participants in dynamically redrawing boundaries around who and what is included and excluded, and thus, as well as our embodied presence, we must also recognise the influence of the cultural artefacts associated with the act of research. Indeed, as Hjorth and $\mathrm{Gu}$ (2012) argue, smartphones narrate a sense of identity, sociality, and place in new ways, shaping how place is experienced and shared co-presently. I discussed earlier how the sudden flourishing of a notebook can disrupt the very field setting that an ethnographer intends to record, but there are also more political aspects 
of research to consider, the statements of wealth, privilege, power, and culture that we make when producing our voice recorders or smartphones; the smartphone is not a neutral artefact.

These issues of power within note-taking are not purely related to a change in recording fieldnotes digitally though. Take, for example, another of Jackson's (2015) interviewees who "had a special notebook [...] it had a Navaho design on the cover" (p.49), or even my own aforementioned flamboyant leather notepad. However, the increased capital of smartphone materiality has the potential to intensify these statements of power and greatly affect researcher-participant relations. Smartphones are highly symbolically charged, signifying affluence and social capital (Hjorth et al., 2012b); the media by which we take our fieldnotes come laden with value statements and social codings. Whilst notebooks can contain designs conveying certain statements and values, smartphones' broader options for personalisation can function as a window into a researcher's personal life in ways that a paper notebook cannot, and care and discretion must be taken; a glimpse of a custom photograph as a background or lock screen can convey large parts of an individual's identity, which has the potential for not just affecting researcher-participant relations, but also in certain contexts, researcher safety. Yet in other cases, this can create the opportunity for a level of similarity to emerge rather than difference; at one stage during my fieldwork, my phone's background wallpaper was set as an image from the popular TV series Game of Thrones, a participant spotted this, and we struck up a conversation and long-lasting rapport as a result. Using a smartphone to take notes can actively influence what happens in the field. 
There is also a need to consider how digital jottings influence the stylistic and elocutionary nature of scratchnotes; due to unamenable spellcheck functions, I found it easier to write things out in full ${ }^{9}$. Emerson et al. (2010) have previously suggested that the idiosyncratic ways in which different researchers record their scratchnotes and jottings, relying on personalised mnemonic keys and private systems of shorthand, can make jotted notes incomprehensible to anyone but the researcher. However, Cliggett (2015) discusses keeping certain material out of efieldnotes in regard to concerns relating to ethical confidentiality and the mobility of digital files, and it is not just the files which have an additional element of mobility, but the devices with which they are recorded too, being a potential target for theft - as Blommaert and Jie (2010) point out "no one has ever expressed an interest in these grotesque note-books" (p.61), introducing new concerns over both confidentiality and data loss. With ethnographers continuing to embrace new technologies we must question whether the changing medium in which fieldnotes are taken subsequently results in a change in the very content of those notes themselves.

\section{Conclusion}

We attach great importance to fieldnotes; they provide the foundational moments of ethnographic representation, turning the situated, ambiguous, and fleeting into a representable and analysable format. There is a need to be more explicit about how fieldnotes are taken however, interrogating phrases such as 'taking notes' and 'doing fieldwork' in order to explore and better recognise the power dynamics 
that exist when conducting ethnographic research. When writing notes within the field, there is a need for reflexivity towards the very mediums through which notes are taken, in order to recognise how the researcher, and the researcher's tools, influence the field.

I have argued and demonstrated that there are place based contingencies to the acceptability of smartphones for taking notes, and that using a smartphone for note-taking purposes can actively influence what happens within the field in ways that more conventional technologies of pen and paper do not. As I have shown, the changing techno-material environments and media through which fieldnotes are created can cause an intensification of power and difference. Reflexive researchers should consider the place based contingencies of how their notetaking devices influence relationships with participants, and the statements of privilege, power, and culture that such tools create. Thought needs to be given to how informed and ethical consent is managed when participant observation is rendered less visible through the everyday associations of the note-taking medium. Digital technologies can act as a boon for researchers, but there is a need to critically recognise the ways in which they modify the field in different fashions than traditional stationery mediums. There is a need to question how this change in materialities within ethnographic practice alters the process of doing research within specific spatial contexts, and how it influences the ethnographic gaze and focus. How we write our notes is as consequential as what we write in our notes.

\section{Acknowledgments}


I'd like to thank members of the CSA farm where this research was conducted for allowing me into their community, and putting up with me being on my phone so much! I also wish to thank Anya Barton, Christopher Bear, and Andrew Williams, as well as Peter Kraftl and the two anonymous reviewers for their insightful feedback on earlier versions of this paper. Above all, thank you to John Clayton, whose guidance, support, teaching and friendship will be greatly missed.

\section{Funding}

This research was conducted as part of a 3 year PhD scholarship, jointly funded by an Economic and Social Research Council studentship (grant reference ES/J500197/1) and a Cardiff University President's Scholarship.

\section{References}

Bingham, N 1996 Object-ions: from technological determinism towards geographies of relations. Environment and Planning D: Society and Space $14635-57$.

Blommaert, J \& Jie, D 2010 Ethnographic Fieldwork Multilingual Matters, Bristol.

Bull, M 2015 Sound moves: iPod culture and urban experience Routledge, Oxon. Burgess, A 2004 Cellular Phones, Public Fears, and a Culture of Precaution Cambridge University Press, Cambridge.

Cliggett, L 2015 Preservation, Sharing, and Technological Challenges of Longitudinal Research in the Digital Age. in Sanjek, R \& Tratner, S W eds eFieldnotes: The Makings of Anthropology in the Digital World. University of Pennsylvania Press, Philadelphia.

Crang, M \& Cook, I 2007 Doing Ethnographies SAGE Publications, London. Crawford, K 2012 Four Ways of Listening with an iPhone: From Sound and Network Listening to Biometric Data and Geolocative Tracking. in Hjorth, 
L, Burgess, J \& Richardson, I eds Studying Mobile Media: Cultural Technologies, Mobile Communication, and the iPhone. Taylor \& Francis, New York.

Desmond, M 2008 On the fireline: Living and dying with wildland firefighters University of Chicago Press, Chicago.

Emerson, R, Fretz, R \& Shaw, L 2010 Writing Ethnographic Fieldnotes University of Chicago Press, Chicago.

Fortunati, L 2002 Italy: stereotypes, true and false. in Katz, J \& Aakhus, M eds Perpetual contact: Mobile communication, private talk, public performance. Cambridge University Press, Cambridge.

Gorman, R 2016 Therapeutic landscapes and non-human animals: the roles and contested positions of animals within care farming assemblages. Social \& Cultural Geography 1-21.

Hjorth, L, Burgess, J \& Richardson, I 2012a Studying the Mobile: Locating the Field. in Hjorth, L, Burgess, J \& Richardson, I eds Studying Mobile Media: Cultural Technologies, Mobile Communication, and the iPhone. Taylor \& Francis, New York.

Hjorth, L \& Gu, K 2012 The place of emplaced visualities: A case study of smartphone visuality and location-based social media in Shanghai, China. Continuum 26 699-713.

Hjorth, L, Wilken, R \& Gu, K 2012b Ambient Intimacy: A Case Study of the iPhone, Presence, and Location-based Social Networking in Shaghai, China. in Hjorth, L, Burgess, J \& Richardson, I eds Studying Mobile Media: Cultural Technologies, Mobile Communication, and the iPhone. Taylor \& Francis, New York.

Jackson, J 1990 "I Am a Fieldnote". in Sanjek, R ed Fieldnotes: The Makings of Anthropology. Cornell University Press, New York.

Jackson, J 2015 Changes in Fieldnotes Practice over the Past Thirty Years in U.S. Anthropology. in Sanjek, R \& Tratner, $\mathbf{S} \mathbf{W}$ eds eFieldnotes: The Makings of Anthropology in the Digital World. University of Pennsylvania Press, Philadelphia.

Kelly, R \& Watts, L 2015 Characterising the inventive appropriation of emoji as relationally meaningful in mediated close personal relationships. European Conference on Computer Supported Cooperative Work 2015. Oslo.

Laurier, E 2003 Participant Observation. in Clifford, N \& Valentine, G eds Key Methods in Geography. SAGE Publications, London.

Lindlof, T \& Taylor, B 2010 Qualitative Communication Research Methods SAGE Publications, London.

Michael, M 2006 Technoscience and everyday life: The complex simplicities of the mundane Open University Press, Berkshire.

Moran, M 2015 The Digital Divide Revisited: Local and Glocal Manifestations in Sanjek, R \& Tratner, S W eds eFieldnotes: The Makings of Anthropology in the Digital World. University of Pennsylvania Press, Philadelphia.

O'Reilly, K 2012 Ethnographic Methods Routledge, Oxon.

Ottenberg, S 1990 Thirty Years of Fieldnotes. in Sanjek, R ed Fieldnotes: The Makings of Anthropology. Cornell University Press, New York.

Parr, H 1998 Mental health, ethnography and the body. Area 30 28-37.

Prensky, M 2001 Digital Natives, Digital Immigrants. On the Horizon 9 1-9. 
Sanjek, R 1990 A Vocabulary for Fieldnotes. in Sanjek, R ed Fieldnotes: The Makings of Anthropology. Cornell University Press, New York.

Sanjek, R \& Tratner, S W 2015 eFieldnotes: The Makings of Anthropology in the Digital World University of Pennsylvania Press, Philadelphia.

Smith, F 2003 Working in Different Cultures. in Clifford, N \& Valentine, G eds Key Methods in Geography. SAGE Publications, London.

Strathern, M 1999 Property, Substance, and Effect: Anthropological Essays on Persons and Things Athlone Press, London.

Strocchi, G 2003 The next frontier of technology: Awaiting UMTS. in Fortunati, L, Katz, J \& Riccini, R eds Mediating the human body: Technology, communication, and fashion. Lawrence Erlbaum Associates, New Jersey.

Tratner, S W 2015 New York Parenting Discussion Boards: eFieldnotes for New Research Frontiers. in Sanjek, $\mathbf{R} \&$ Tratner, $\mathbf{S} \mathbf{W}$ eds eFieldnotes: The Makings of Anthropology in the Digital World. University of Pennsylvania Press, Incorporated, Philadelphia.

Williams, A 2016 Residential ethnography, mixed loyalties, and religious power: ethical dilemmas in faith-based addiction treatment. Social \& Cultural Geography.

\footnotetext{
${ }^{1}$ Along with Emerson et al.'s (2010) attempts to redress this, Crang and Cook (2007) also provide an exception to this general trend.

2 Though in this regard, it is also worth recognising that digital technologies like smartphones 'extend the office' as well, creating a sense of 'being in the field, but not', as well as expanding the potential for Ottenberg's (1990) point about fieldnotes resulting in having someone else 'present' in the field with you. 3 Obviously the 'everyday-ness' of the smartphone is inherently contextual and place-bound.

4 Though it is worth recognising here that relations with technology are fundamentally temporally influenced, and cultural value and social acceptance changes over time. Thus in future, digital forms of note-taking may come to be as embedded in popular imaginings of 'research' as much as paper-bound ones currently. Already there is a trend towards the phone as an everyday object, whereas in previous discussions it has been regarded as a much more class bound object (Burgess, 2004). Changes occur in the 'aura' of particular technological objects, and where it may have been brash to display a phone previously, is now more socially acceptable as ownership becomes more normalised and everyday.

${ }^{5}$ Community Supported Agriculture is a system of food production and distribution aiming to involve local communities in the growing and rearing of their food.

${ }^{6} \mathrm{~A}$ backlit screen makes the taking of notes much easier than scribbling in the dark - Crang and Cook (2007) note the problematic issue of being unable to decipher nocturnally written scratchnotes.

7 Though, drawing on Fortunati (2002), it is worth recognising that even when phones are not actively being used, they retain a level of visibility; their positions on the body are precarious and unstable, unable to be fully incorporated into clothing, secreted in pockets, yet remaining visible.
} 
8 The element of a built in camera in many smartphones can result in further place-based restrictions in this regard.

${ }^{9}$ On this point, 'Emoji' (two dimensional pictographs built in to most smartphones) possess a high potential for creating meaning (Kelly and Watts, 2015), potentially providing new routes for ethnographers to quickly take useful and personal scratchnotes. 